\title{
Research of the Effect of Diphenylguanidine on the Adhesive Interaction of Elastomers with Ultrahigh Molecular Weight Polyethylene
}

\author{
Afanasiy A. Dyakonov*a, Nikolay V. Shadrinov ${ }^{a, b}$, \\ Marina D. Sokolova ${ }^{\mathrm{b}}$, Andrey L. Fedorov ${ }^{\mathrm{a}, \mathrm{b}}$, \\ Sardana A. Sleptsova ${ }^{\mathrm{a}}$ and Aitalina A. Okhlopkova ${ }^{\mathrm{a}, \mathrm{b}}$ \\ ${ }^{a}$ North-Eastern Federal University \\ 58 Belinsky Str., Yakutsk, 677000, Russia \\ ${ }^{b}$ Institute of Oil and Gas Problems SB RAS \\ 20 Avtodorozhnaya Str., Yakutsk, 677021, Russia
}

Received 03.09.2018, received in revised form 12.11.2018, accepted 15.05.2019

The paper presents the technology of manufacturing of a double-layered material based on ultrahigh molecular weight polyethylene on one side and an elastomer on the other, which has high adhesive strength between materials. The results of the study of the adhesive interaction of ultrahigh molecular weight polyethylene with elastomers based on various rubbers are presented. The dependence of the strength of adhesive interaction between materials on the diphenylguanidine curing agents content in the rubber compound is shown in the article. It was found that with the addition of diphenylguanidine, the strength of the adhesive bond between the materials exceeds the cohesive strength of the elastomer and the process of delamination at fracture occurs along rubber. The study of the interphase boundary on a scanning electron microscope showed that the addition of diphenylguanidine into the rubber mixture leads to a change in the structure of ultrahigh molecular weight polyethylene to fine-spherulite. Using the method of IR-spectroscopy it was detected the peaks of stretching vibrations, corresponding to $C$-S bonds, and peaks corresponding to stretching vibrations of R-SO-OR and RO-SO-OR groups with the addition of diphenylguanidine into the rubber mixture in the ultrahigh molecular weight polyethylene structure near the interphase boundary.

Keywords: double-layered material, rubber, ultrahigh molecular weight polyethylene, adhesion, nitrile butadiene rubber, butadiene-styrene rubber, isoprene rubber, diphenylguanidine.

Citation: Dyakonov A.A., Shadrinov N.V., Sokolova M.D., Fedorov A.L., Sleptsova S.A., Okhlopkova A.A. Research of the Effect of Diphenylguanidine on the Adhesive Interaction of Elastomers with Ultrahigh Molecular Weight Polyethylene, J. Sib. Fed. Univ. Eng. technol., 2019, 12(4), 487-498. DOI: 10.17516/1999-494X-0156.

(C) Siberian Federal University. All rights reserved

This work is licensed under a Creative Commons Attribution-NonCommercial 4.0 International License (CC BY-NC 4.0).

* Corresponding author E-mail address: afonya71185@mail.ru 


\title{
Исследование влияния дифенилгуанидина
}

\author{
на адгезионное взаимодействие эластомеров \\ со сверхвысокомолекулярным полиэтиленом
}

\begin{abstract}
А.А. Дьяконов А.Л. Федоров ${ }^{\mathrm{a}, \boldsymbol{\sigma}}$, С.А. Слепцова ${ }^{\mathrm{a}}$, А.А. Охлопкова ${ }^{\mathrm{a}, \boldsymbol{\sigma}}$

${ }^{a}$ Северо-Восточный федеральный университет Россия, 677000, Якутск, ул. Белинского, 58

${ }^{6}$ Институт проблем нефти и газа СО РАН

Россия, 677021, Якутск, ул. Автодорожная, 20
\end{abstract}

В работе представлена технология изготовления двухслойного материала на основе сверхвысокомолекулярного полиэтилена и эластомера, обладающего высокой адгезионной прочностью между материалами. Приведень результаты исследования адгезионного взаимодействия сверхвысокомолекулярного полиэтилена с эластомерами на основе различных каучуков. Показаназависимость прочности адгезионного взаимодействиямеждуматериалами от вулканизационной группы, в частности от содержания дифенилгуанидина в резиновой смеси. Установлено, что при введении дифенилгуанидина прочность адгезионного соединения между материалами превыпает когезионную прочность эластомера и при расслоении разрушение происходит по резине. При исследовании межфазной границы на растровом электронном микроскопе было обнаружено, что при введении дифенилгуанидина в резиновую смесь структура сверхвысокомолекулярного полиэтилена меняется на мелкосферолитную. С помощью метода ИК-спектроскопии установлено, что при введении дифенилгуанидина в резиновую смесь в структуре сверхвысокомолекулярного полиэтилена вблизи межфазной границы появляются пики валентных колебаний, соответствующие $C$-S-связям, а также уширяются пики, соответствующие валентным колебаниям R-SO-OR- u RO-SO-OR-групп.

Ключевые слова: двухслойный материал, резина, сверхвысокомолекулярный полиэтилен, адгезия, бутадиен-нитрильный каучук, бутадиен-стирольный каучук, изопреновый каучук, дифенилгуанидин.

\section{Введение}

Несмотря на большое разнообразие полимерных материалов, обладающих уникальными свойствами, по-прежнему актуальна задача по изготовлению новых композиционных материалов с улучшенными эксплуатационными свойствами [1-3].

Одним из перспективных направлений считается создание материалов на основе комбинации полимерных и эластомерных материалов. На основе комбинированных полимеров можно не только получать материалы, сочетающие в себе свойства отдельных полимеров, но и добиваться того разнообразия свойств, которого невозможно достичь при использовании одного полимера или эластомера $[4,5]$. Одно из таких решений - создание двухслойного материала на основе эластомера и сверхвысокомолекулярного полиэтилена (СВМПЭ) (рис. 1), сочетающего в себе свойства двух разных материалов. Благодаря высокой эластичности резины и уникальным свойствам СВМПЭ (высокие упруго-прочностные свойства, износостойкость, низкий коэффициент трения) [6] на основе двухслойного материала могут быть изготовлены резинотехнические изделия, способные эксплуатироваться в контакте с различными агрессивными средами,

$$
\text { - } 477 \text { - }
$$




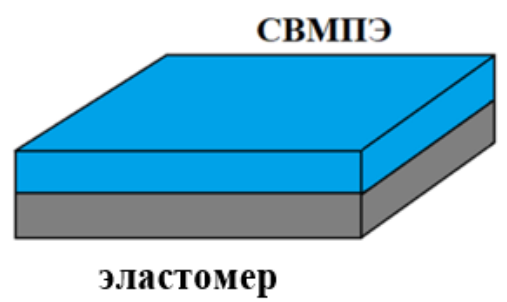

Рис. 1. Двухслойный материал на основе эластомера и СВМПЭ

Fig. 1. Double-layered material based on elastomer and UHMWPE

а также при повышенных давлениях в широком интервале рабочих температур. Надежность такого двухслойного материала в основном зависит от прочности адгезионного соединения эластомера с СВМПЭ. Таким образом, цель данной работы заключается в исследовании влияния ингредиентов резиновой смеси на адгезионное взаимодействие между эластомером и СВМПЭ, в частности дифенилгуанидина (ДФГ), который является ускорителем вулканизации.

\section{Материалы и методы исследования}

В работе приведены результаты исследования влияния ДФГ на адгезионное взаимодействие между СВМПЭ марки GUR-4113 со средней молекулярной массой 3,9 млн г/моль и эластомерами на основе бутадиен-нитрильного (БНКС-18), изопренового (СКИ-3) и бутадиенстирольного (СКС-30) каучуков [7].

Исследования проведены на резиновых смесях на основе БНКС-18, СКИ-3 и СКС-30 следующего состава (масс. ч.): каучук - 100,0; технический углерод N774 - 50,0; сера - 2,0; ускоритель вулканизации (каптакс) - 1,5; активаторы: $\mathrm{ZnO}-5,0$; стеариновая кислота $-2,0$ и ДФГ - 0,1, 0,2 и 0,3 .

Известно [8], что СВМПЭ и резины на основе БНКС-18, СКИ-3 и СКС-30 являются термодинамически несовместимыми полимерами. Однако благодаря тому, что в процессе совместного горячего прессования, при котором происходит вулканизация резин под воздействием высокой температуры (от 143 до $180^{\circ} \mathrm{C}$ ) и давления, СВМПЭ переходит в аморфное состояние (температура плавления CBMПЭ GUR-4113 от $128{ }^{\circ} \mathrm{C}$ ) и образует адгезионное соединение с эластомером.

В связи с этим предложен следующий способ изготовления двухслойного композиционного материала, состоящий из 4-х этапов:

- I этап. Холодное формование СВМПЭ в пресс-форме под давлением 90 кгс/см² в течение 5 мин при комнатной температуре;

- II этап. Равномерное укладывание слоя резиновой смеси поверх формованного СВМПЭ;

- III этап. Совместное горячее прессование слоев СВМПЭ и резиновой смеси при темпе-

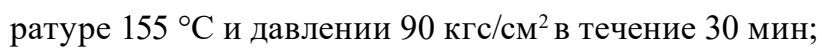

- IV этап. Охлаждение образца до $60^{\circ} \mathrm{C}$ в пресс-форме под давлением [9].

Исследование прочности адгезионного соединения между эластомерами и СВМПЭ проводилось по аналогии с ГОСТ 6768-75 на разрывной машине Shimadzu Autograph (Shimadzu,

$$
-478-
$$


Япония). Упруго-прочностные свойства изготовленных эластомерных материалов исследованы на разрывной машине Shimadzu Autograph согласно ГОСТ 270-75. Стойкость к воздействию жидких агрессивных сред IRM-901 в ненапряженном состоянии исследована согласно ГОСТ 9.030-74, твердость - по методу Шор А. Исследование структуры межфазного граничного слоя эластомера и СВМПЭ проводилось на растровом электронном микроскопе JEOL JSM-7800F (JEOL, Япония). Исследование межфазного граничного слоя эластомера и СВМПЭ проводили на ИК-спектрометре с Фурье-преобразованием Varian 7000 FT-IR (Varian, США). ИК-спектры получали с помощью приставки нарушенного полного внутреннего отражения (НПВО) в диапазоне 800-4000 $\mathrm{cm}^{-1}$.

\section{Результаты и обсуждение}

Термодинамически несовместимые полимерные материалы могут образовывать прочное адгезионное соединение за счет формирования новых химических связей на границе раздела фаз. Для увеличения адгезии между эластомерами и СВМПЭ в резиновую смесь вводили ускоритель вулканизации - ДФГ, способствующий образованию полисульфидных связей между макромолекулами каучука и СВМПЭ по ионному механизму [10]. Исследовались следующие концентрации ДФГ: 0,$1 ; 0,2$ и 0,3 масс. ч. на 100 масс. ч. каучука.

Результаты исследования свойств эластомеров на основе БНКС-18, СКИ-3 и СКС-30 в зависимости от содержания ДФГ представлены в табл. 1.

Введение ДФГ в резиновую смесь на основе БНКС-18 приводит к снижению прочности и относительному удлинению по сравнению с эластомером, не содержащим ДФГ. С увеличением содержания ДФГ в эластомере наблюдается повышение напряжения при $100 \%$-м удлинении, а относительное удлинение при разрыве снижается. Наибольшее значение прочности

Таблица 1. Свойства вулканизатов на основе БНКС-18, СКИ-3 и СКС-30 в зависимости от концентрации ДФГ

Table 1. Properties of vulcanizates based on NBR, IR, SBR, depending on the concentration of DPG

\begin{tabular}{|c|c|c|c|c|c|c|c|c|c|c|c|c|}
\hline \multirow{2}{*}{ Ингредиенты } & \multicolumn{12}{|c|}{ Рецептуры } \\
\hline & 1 & 2 & 3 & 4 & 5 & 6 & 7 & 8 & 9 & 10 & 11 & 12 \\
\hline Тип каучука & \multicolumn{4}{|c|}{ БНКС-18 } & \multicolumn{4}{|c|}{ СКИ-3 } & \multicolumn{4}{|c|}{ CKC-30 } \\
\hline ДФГ, масс. ч. & 0 & 0,1 & 0,2 & 0,3 & 0 & 0,1 & 0,2 & 0,3 & 0 & 0,1 & 0,2 & 0,3 \\
\hline \multicolumn{13}{|c|}{ Свойства вулканизатов } \\
\hline Показатели & 1 & 2 & 3 & 4 & 5 & 6 & 7 & 8 & 9 & 10 & 11 & 12 \\
\hline$\varepsilon p, \%$ & 410 & 313 & 303 & 285 & 707 & 724 & 689 & 666 & 688 & 417 & 414 & 343 \\
\hline $\mathrm{fp}, \mathrm{MПа}$ & 10,7 & 8,2 & 8,1 & 10,1 & 7,2 & 14,4 & 14,1 & 14,2 & 15,9 & 11,1 & 11,6 & 9,4 \\
\hline $\mathrm{f}_{100 \%}, \mathrm{M \Pi а}$ & 2,6 & 2,5 & 2,9 & 3,0 & 0,7 & 1,3 & 1,3 & 1,3 & 1,9 & 2,3 & 2,4 & 2,5 \\
\hline Н, Шор A & 64 & 62 & 63 & 67 & 41 & 62 & 67 & 69 & 62 & 62 & 63 & 63 \\
\hline$\rho, \Gamma / \mathrm{CM}^{3}$ & 1,16 & 1,16 & 1,15 & 1,15 & 1,13 & 1,12 & 1,12 & 1,12 & 1,17 & 1,16 & 1,16 & 1,15 \\
\hline${ }_{\Delta} \mathrm{Q}, \%$ & 8,3 & 8,3 & 7,9 & 6,8 & 202 & 129 & 140 & 116 & 41 & 39 & 34 & 36 \\
\hline
\end{tabular}

Примечание: $\varepsilon p, \%$ - относительное удлинение при разрыве; fp, МПа - условная прочность при разрыве; $\mathrm{f}_{100 \%}, \mathrm{MПа} \mathrm{-}$ условное напряжение при удлинении 100 \%; Н, Шор А - твердость по Шору А; $\rho$, г/см ${ }^{3}$ - плотность; $\Delta \mathrm{Q}, \%$ - степень набухания в среде IRM-901. 
при разрыве наблюдается у образца, содержащего 0,3 масс. ч. ДФГ - 10,1 МПа, что на 23 и $25 \%$ больше, чем у резин с содержанием 0,1 и 0,2 масс. ч. ДФГ соответственно. С увеличением концентрации ДФГ в эластомерах повышается твердость по Шору А. и стойкость к воздействию масла IRM-901, плотность эластомеров существенно не меняется (изменение на $\left.-0,01 \Gamma / \mathrm{cm}^{3}\right)$.

Добавление ДФГ в резиновую смесь на основе каучука СКИ-3 приводит к увеличению прочности при разрыве в 2 раза относительно эластомеров без ДФГ. Известно [11], что резины на основе изопреновых каучуков, содержащих комбинацию ускорителей каптакса и ДФГ, за счет синергетического эффекта обладают большей прочностью при разрыве по сравнению с резинами с отдельными ускорителями. Увеличение прочности происходит за счет образования большего количества поперечных связей между макромолекулами изопренового каучука и повышения скорости вулканизации смесей. Добавление 0,1 масс. ч. ДФГ увеличивает прочностные свойства в 2 раза, с дальнейшим увеличением содержания ДФГ происходит незначительное изменение прочности и снижение относительного удлинения при разрыве. Условное напряжение при растяжении на 100 \% остается практически неизменным. С увеличением концентрации ДФГ в составе резиновой смеси на основе СКИ-3 повышается твердость по Шору А. (до $~ 1,7$ раз) и стойкость к IRM-901 на 73-86 \% относительно образца без ДФГ.

Введение ДФГ в резиновую смесь на основе СКС-30 приводит к снижению упругопрочностных показателей, при этом увеличивается условное напряжение при удлинении на 100 \%. При концентрации 0,3 масс. ч. ДФГ прочность при разрыве снижается на 41 \%, относительное удлинение на $-345 \%$, плотность существенно не изменяется. При увеличении концентрации ДФГ в составе смеси СКС-30 снижается степень набухания в масле IRM-901. Применение комбинации ускорителей также приводит к сокращению времени активации вулканизующих агентов [12]. Однако возникает риск перевулканизации, которая, в первую очередь, проявляется в повышении жесткости и снижении прочности вулканизатов [13].

Исследование адгезии между СВМПЭ и резинами на основе БНКС-18, СКИ-3 и СКС-30 показало, что введение в состав резиновой смеси ДФГ влечет за собой повышение прочности адгезионного соединения. Разрушение при расслоении двухслойных образцов, не содержащих ДФГ в составе резиновой смеси, происходит по границе раздела фаз между резиной и СВМПЭ (рис. 2a), это свидетельствует о недостаточности адгезии. При введении ДФГ в резиновую смесь разрушение при расслоении двухслойных образцов случается либо комбинированно (рис. 26), либо по резине (рис. 26). Комбинированное расслоение происходит частично по границе раздела фаз и частично по одному из материалов. Расслаивание по резине идет в случае, если адгезионное соединение между СВМПЭ с эластомером превышает прочность одного из материалов, и разрушение носит когезионный характер.

На рис. 3 представлена зависимость прочности адгезии между резиной и СВМПЭ от концентрации ДФГ, введенного в состав резиновых смесей на основе БНКС-18, СКИ-3 и СКС-30.

Как видим на рис. 3, с увеличением концентрации ДФГ в резиновой смеси происходит увеличение адгезии между каучуками и СВМПЭ. При введении 0,1-0,2 масс. ч. ДФГ расслоение образцов СКС-30 и БНКС-18 от СВМПЭ идет комбинированно. При введении 0,3 масс. ч. ДФГ 


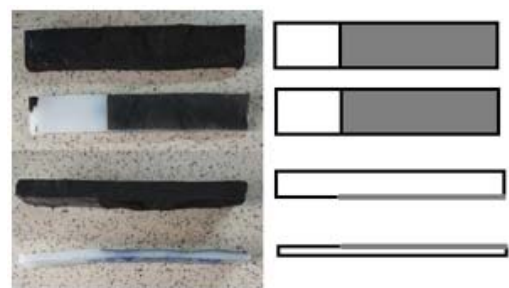

a)

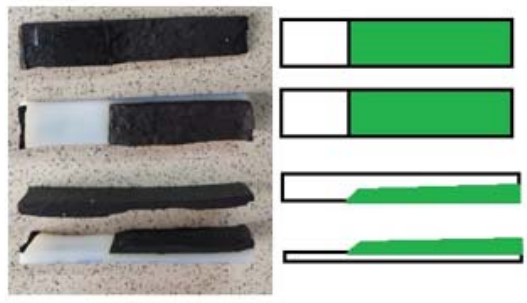

B)

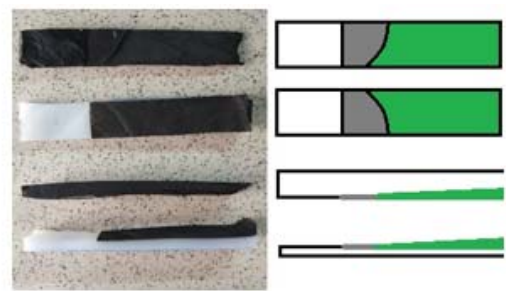

б)

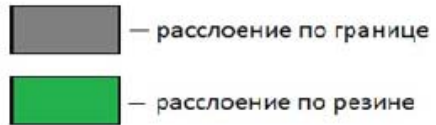

Рис. 2. Характер расслоения двухслойных материалов: а - расслоение по границе раздела фаз между резиной и СВМПЭ; б - комбинированное расслоение; в - расслоение по резине

Fig. 2. The nature of delamination of double-layered materials: a - delamination along the interphase boundary between the rubber and ultrahigh molecular weight polyethele (UHMWPE); 6 - combined stratification; в - rubber stratification

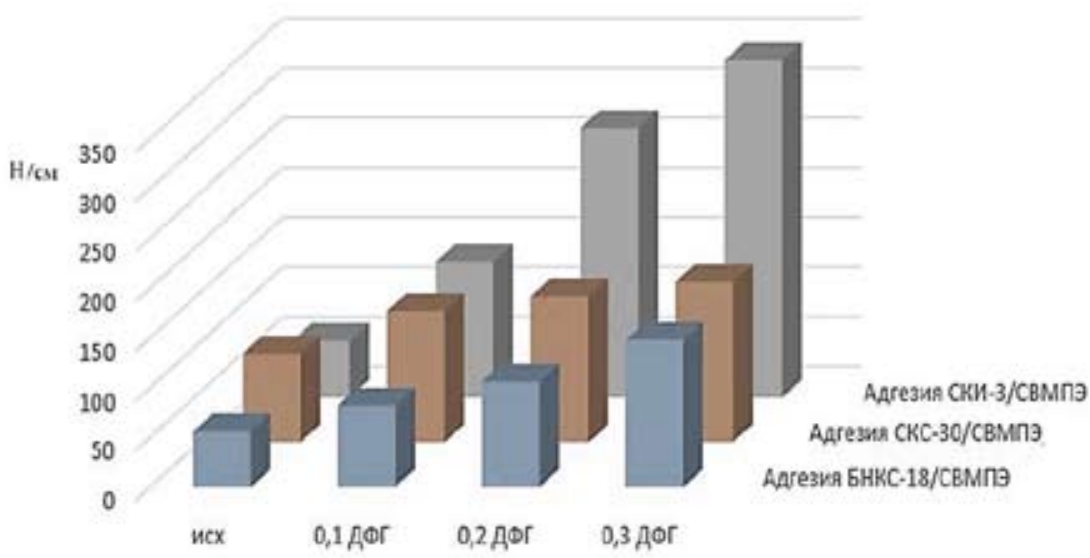

Рис. 3. Влияние концентрации ДФГ на адгезионное взаимодействие между СВМПЭ и эластомерами на основе БНКС-18, СКИ-3 и СКС-30

Fig. 3. The effect of diphenylguanidine (DPG) concentration on the adhesive interaction between UHMWPE and elastomers based on NBR (nitrile butadiene rubber), IR (isoprene rubber) and SBR (styrene-butadiene rubber)

расслоение происходит по резине, что свидетельствует о том, что адгезия превышает когезионную прочность материала. Расслоение СВМПЭ от резины на основе СКИ-3 случается комбинированно при 0,1 масс. ч. ДФГ, с увеличением содержания ДФГ расслоение носит когезионный характер.

Повышение адгезионного взаимодействия между резиной и СВМПЭ при введении ДФГ в эластомерную смесь можно объяснить тем, что в процессе вулканизации ДФГ вступает в 
реакцию с элементарной серой $[10,14]$, содержащейся в составе резиновой смеси, и раскрывает восьмичленный серный цикл по ионному механизму (рис. 4).

Возможно, высокореакционноспособное разорванное серное кольцо вступает в реакцию не только с макромолекулами каучука, но и с макромолекулами СВМПЭ, которые под действием высокого давления и температуры плотно приближаются к эластомерной матрице, т.е. образуют сульфидные связи с макромолекулами каучука, с одной стороны, и СВМПЭ - с другой. Повышение концентрации ДФГ приводит к повышению количества сульфидных связей, что вызывает увеличение прочности адгезионного соединения. Схематическое изображение образования серных связей между макромолекулами каучука и СВМПЭ представлено на рис. 5.

Образование сульфидных связей в макромолекулах полиэтилена (ПЭ) в присутствии серы, ДФГ и каптакса было ранее установлено в других научных работах $[10,15,16]$. Показано, что добавление ДФГ при сульфировании ПЭ способствует образованию сульфидных связей между его макромолекулами по ионному механизму. Применение отдельно каптакса как катализатора взаимодействия серы с ПЭ не обеспечивает образования достаточного количества серных связей для формирования прочного адгезионного соединения.

Добавление ДФГ в резиновую смесь приводит к изменению надмолекулярной структуры СВМПЭ в области межфазной границы с эластомерами, наблюдается образование мелкосферолитной структуры. На рис. $6 a, 6, \partial$ представлены снимки границы СВМПЭ с

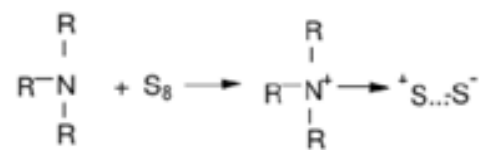

Рис. 4. Процесс активации распада серного цикла по ионному механизму

Fig. 4. The activation process of the decay of the sulfur cycle by the ionic mechanism

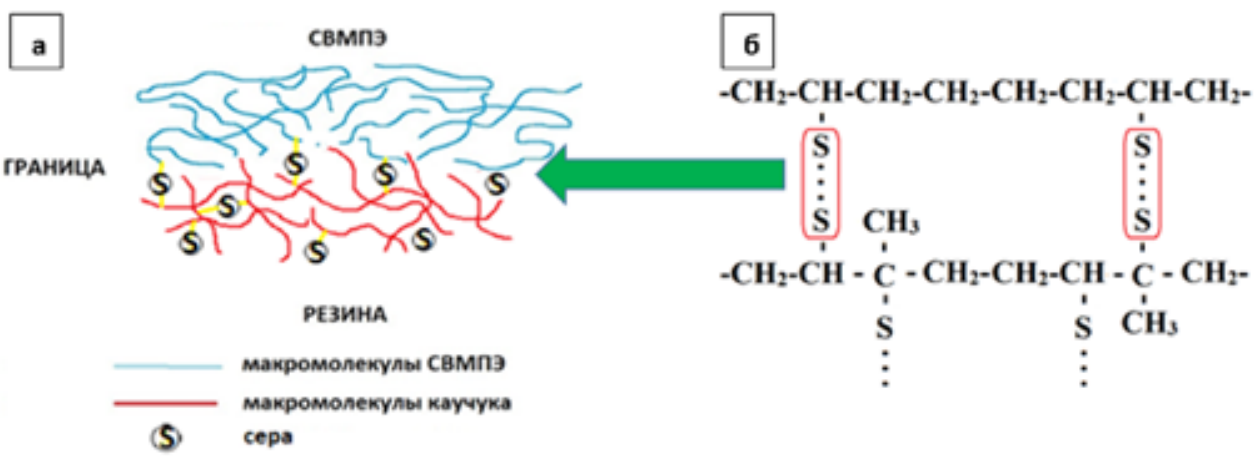

Рис. 5. Образование сульфидных связей между макромолекулами каучука СКИ-3 и СВМПЭ: а схематическое изображение образования сульфидных связей; б - химическая структура образования сульфидных мостиков на межфазной границе СВМПЭ и изопренового каучука

Fig. 5. The formation of sulfide bonds between macromolecules of isoprene rubber and UHMWPE: a - a schematic representation of the formation of sulfide bonds; $\sigma$ - the chemical structure of the formation of sulfide bridges at the interphase boundary of UHMWPE and isoprene rubber 

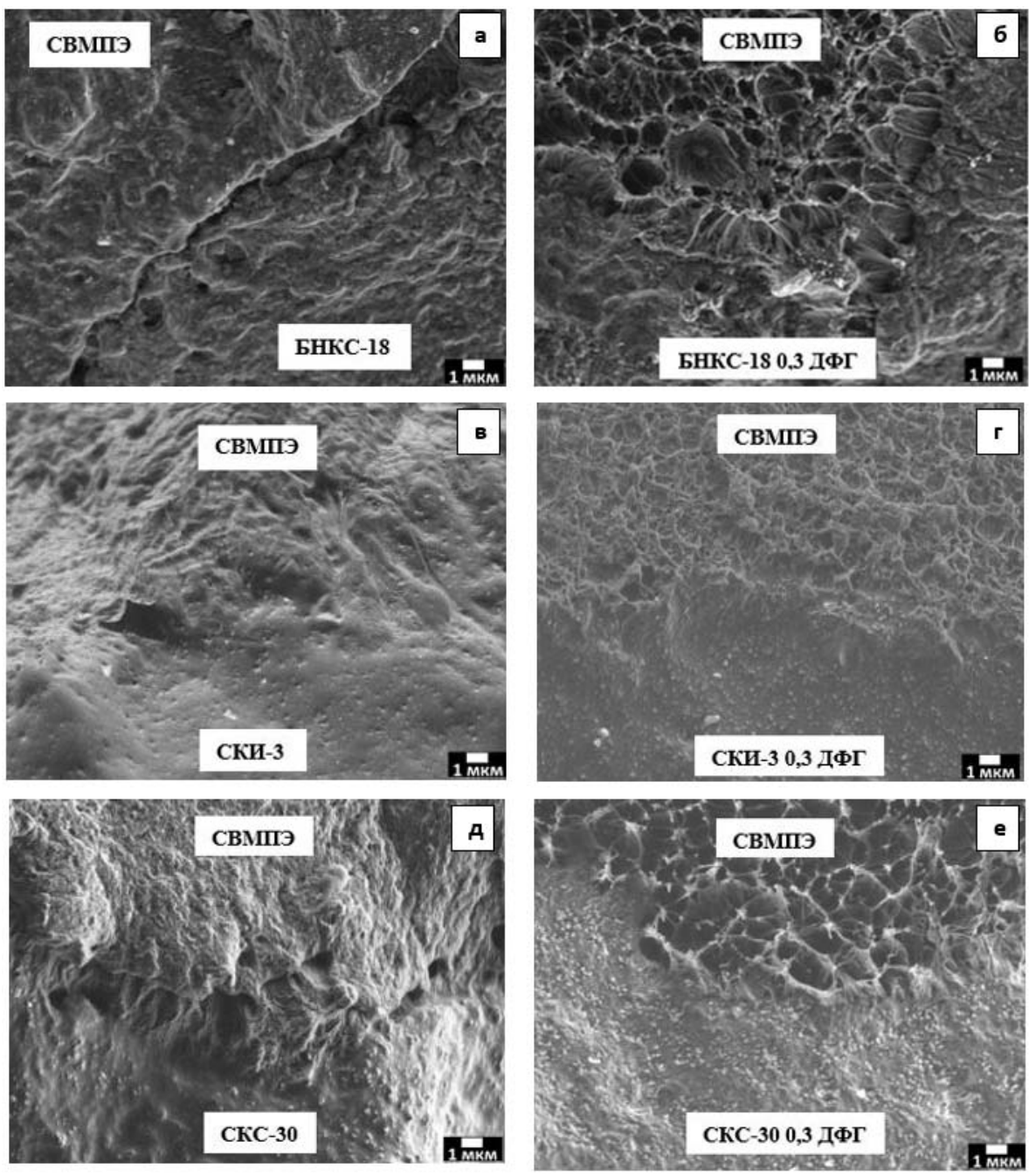

Рис. 6. Микрофотографии переходного слоя СВМПЭ с эластомерами: а - БНКС-18; б - БНКС-18 + 0,3 масс. ч. ДФГ; в - СКИ-3; г - СКИ-3 + 0,3 масс. ч. ДФГ; д - СКС-30; е - СКС-30 + 0,3 масс. ч. ДФГ

Fig. 6. Micrographs of the transition layer of UHMWPE with elastomers: a - NBR; $6-\mathrm{NBR}+0.3$ phr DPG; в IR; г-IR + 0.3 phr DPG; д - SBR; e - SBR + 0.3 phr DPG

резиной без добавления ДФГ, на рис. 6б, г, е-с добавлением 0,3 масс. ч. ДФГ. Структурные граничные изменения могут указывать на образование серных соединений между СВМПЭ и эластомерами, что, в свою очередь, способствует увеличению адгезионного взаимодействия.

Для подтверждения гипотезы об образовании сульфидных соединений между макромолекулами каучука и СВМПЭ исследована структура СВМПЭ вблизи его межфазной границы с эластомерами методом ИК-спектроскопии с помощью НПВО. На рис. 7 приведены ИК-спектры, где видно, что введение ДФГ в резиновую смесь БНКС-18, СКИ-3 и СКС-30 вызывает изменение получаемых спектров:

- при наличии ДФГ в резиновой смеси исчезают пики при $\sim 1710 \mathrm{~cm}^{-1}$, которые могут свидетельствовать о наличии несопряженных $-\mathrm{C}=\mathrm{C}$-связей каучуков, а также о наличии 

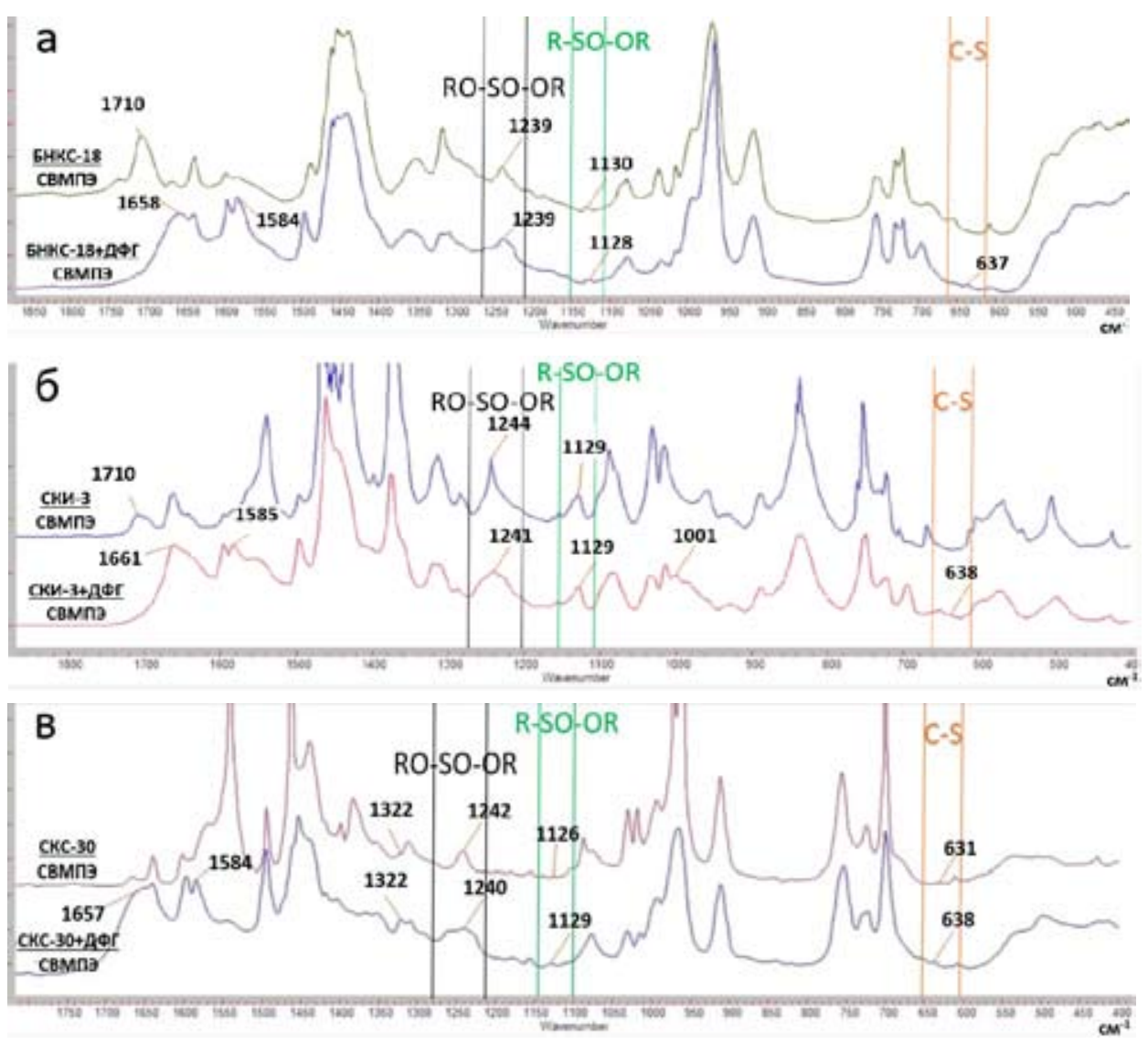

Рис. 7. ИК-спектры образцов резин в области межфазной границы между СВМПЭ и эластомером: а СВМПЭ/БНКС-18 и СВМПЭ/(БНКС-18+ДФГ); б - СВМПЭ/СКИ-3 и СВМПЭ/(СКИ-3+ДФГ); в - СВМПЭ/ СКС-30 и СВМПЭ/(СКС-30+ДФГ)

Fig. 7. IR spectra of rubber samples in the region of the interphase boundary between UHMWPE and elastomer: a - UHMWPE / NBR and UHMWPE / (NBR + DPG); 6 - UHMWPE / IR and UHMWPE / (IR + DPG); в - UHMWPE / SBR and UHMWPE / (SBR + DPG)

валентных колебаний карбонильной группы $(\alpha, \beta$ непредельные $\mathrm{C}=\mathrm{C}-\mathrm{COOH})$, которые образуются в результате окислительных процессов. Исчезновение данных пиков при введении ДФГ связано с интенсификацией процесса вулканизации, в ходе которого сера в первую очередь разрушает двойные связи;

- появляются пики при $\sim 1658$ cм$^{-1}$, соответствующие валентным колебаниям C=N-Oгрупп (оксимы) [17], которые образуются в результате окисления иминной группы $(\mathrm{C}=\mathrm{N}-\mathrm{H})$, имеющийся в составе молекулы ДФГ [18];

- появляются пики при $1584 \mathrm{~cm}^{-1}$, соответствующие плоским деформационным колебаниям первичных аминов $\left(-\mathrm{NH}_{2}\right)$, которые получаются в результате таутомерии ДФГ, где иминная группа $(\mathrm{C}=\mathrm{NH})$ превращается в аминную $\left(\mathrm{C}-\mathrm{NH}_{2}\right)$ [19].

Однако основной интерес вызывает то, что при введении ДФГ в резиновую смесь в структуре СВМПЭ вблизи межфазной границы появляются (более сильно проявляются) пики при $\sim 630 \mathrm{~cm}^{-1}$, соответствующие валентным колебаниям C-S-связей и уширяются пики при 1129 
и $1240 \mathrm{~cm}^{-1}$, соответствующие валентным колебаниям R-SO-OR- и RO-SO-OR-групп. Появление данных пиков, а также их уширение могут свидетельствовать о том, что ДФГ раскрывает серный цикл и сера более активно вступает во взаимодействие с макромолекулами не только каучука, но и СВМПЭ, образуя сульфидные группы, которые влияют на прочность адгезионного взаимодействия.

\section{Заключение}

В работе установлено, что прочность соединения между эластомерами и СВМПЭ зависит от вулканизационной группы. Введение 0,3 масс. ч. ДФГ в резиновую смесь на основе БНКС18, СКИ-3 и СКС-30 каучуков приводит к повышению адгезии между слоями, и в процессе расслоения двухслойного материала разрушение происходит по приграничному резиновому слою. Адгезия между слоями превышает когезионную прочность резины.

Установлено, что введение ДФГ в резиновую смесь приводит к изменению надмолекулярной структуры СВМПЭ вблизи межфазной границы. Надмолекулярная структура СВМПЭ преобразуется в мелкосферолитную, что обуславливается протеканием химических реакций на границе взаимодействия.

Выявлено, что при введении ДФГ в резиновую смесь в структуре СВМПЭ вблизи межфазной границы появляются пики, соответствующие валентным колебаниям C-S-связей, а также уширяются пики, соответствующие валентным колебаниям R-SO-OR- и RO-SO-OR-групп. Появление данных пиков и их уширение согласуются с тем утверждением, что ДФГ раскрывает серный цикл и сера более активно вступает во взаимодействие с макромолекулами не только каучука, но и СВМПЭ, образуя сульфидные группы, которые влияют на прочность адгезионного взаимодействия.

Работа выполнена при финансовой поддержке МНиВО РФ НИР № FSRG-2017-0021, FSRG-2017-0017 и РФФИ № 16-33-60070 «Исследование влияния наполнителей на деформационные свойства полимерных композиционных материалов в нанометровом диапазоне».

\section{Список литературы}

[1] Carraher Jr.C.E., Currell, B., Pittman, Jr., C., Sheats, J., Zeldin, M. Inorganic and MetalContaining Polymeric Materials. Springer Science \& Business Media, 2012. 517 p.

[2] Turi E. Thermal characterization of polymeric materials. Elsevier, 1981. 972 p.

[3] Zyss J. Molecular nonlinear optics: materials, physics, and devices. Academic press, 2013. $478 \mathrm{p}$.

[4] Dyakonov A.A., Sokolova M.D., Shadrinov N.V., Sleptsova S.A. Application of protective coatings from ultrahigh-molecular weight polyethylene to butadiene-nitrile rubber. AIP Conference Proceedings 1909, 020037 (2017).

[5] Гринберг П.Б., Полещенко К.Н., Суриков В.И., Тарасов Е.Е. Технология нанесения наноструктурированных металлопокрытий на резинотехнические изделия. Вестник Омского университета, 2012, 2 (64), 249-252 [Grinberg P.B., Poleshchenko K.N., Surikov V.I., Tarasov Ye.Ye. Technology of deposition of nanostructured metal coatings on rubber products. Herald Of Omsk University, 2012, 2 (64), 249-252 (in Russian)] 
[6] Андреева И.Н., Веселовская Е.В., Наливайко Е.И. Сверхвысокомолекулярный полиэтилен высокой плотности. Л: Химия, Т. 5, 1982. 48 с. [Andreyeva I.N., Veselovskaya Ye.V., Nalivayko Ye.I. Ultrahigh molecular weight polyethylene of high density. L: Chemistry, Vol. 5, 1982. 48 p. (in Russian)]

[7] Чайкун А.М., Елисеев О.А., Наумов И.С., Венедиктова М.А. Особенности морозостойких резин на основе различных каучуков. Труды ВИАМ, 2013, №12 [Chaykun A.M., Yeliseyev O.A., Naumov I.S., Venediktova M.A. Features Of Cold-Resistant Curing Rubber Compounds On The Basis Of Different Rubbers. Proceedings of VIAM, 2013, 12 (in Russian)]

[8] Давыдова М.Л., Шадринов Н.В. Полимер-эластомерные нанокомпозиты на основе бутадиен-нитрильной резины, сверхвысокомолекулярного полиэтилена и природного цеолита. Перспективные материалы, 2010, 9, 283-288 [Davydova M.L., Shadrinov N.V. Polymer-elastomeric nanocomposites based on nitrile-butadiene rubber, ultra-high molecular weight polyethylene and natural zeolite. Journal of Advanced Materials, 2010, 9, 283-288 (in Russian)]

[9] Соколова М.Д., Дьяконов А.А., Попов С.Н., Шадринов Н.В., Морова Л.Я., Охлопкова А.А., Слепцова С.А. Поверхностно-модифицированный композиционный материал. Патент РФ № 2615416, бюл. № 10 от 04.04.2017 [Sokolova M.D., Dyakonov A.A., Popov S.N., Shadrinov N.V., Morova L.Y., Okhlopkova A.A., Sleptsova S.A. Surface-modified composite material. RF patent No. 2615416, bull. No. 10 from 04/04/2017 (in Russian)]

[10] Карасева Ю.С., Башкатова Т.В., Черезова Е.Н., Хусаинов А.Д. Исследование продуктов взаимодействия полиэтилена с серой в качестве вулканизующих агентов. Вестник Казанского технологического университета, 2006, 5, 57-62 [Karaseva Yu.S., Bashkatova T.V., Cherezova Ye.N., Khusainov A.D. The study of the products of the interaction of polyethylene with sulfur as a vulcanizing agent. Bulletin of the Technological University, 2006, 5, 57-62 (in Russian)]

[11] Akiba M., Hashim A.S. Vulcanization and crosslinking in elastomers. Progress in polymer science, 1997, 22(3), 475-521.

[12] Блох Г.А. Органические ускорители вулканизаџии и вулканизующие системы для эластомеров. Л.: Химия, 1978. 240 с. [Bloh G.A. Organic vulcanization accelerators and vulcanizing systems for elastomers. L.: Chemistry, 1978. 240 p. (in Russian)]

[13] Мухутдинов Э.А., Дьяконов Г.С. Физико-химические основы ослабления старения резин на примере комплексных ингибиторов. Вестник Казанского технологического универcumema, 2010, 10, 483-504 [Mukhutdinov E.A., Dyakonov G.S. Physical and chemical bases of aging of rubbers on the example of complex inhibitors. Bulletin of the Technological University, 2010, 10, 483-504 (in Russian)]

[14] Гофман В. Вулканизаџия и вулканизующие агенты. Л.: Химия, 1968. 291 c. [Gofman V. Vulcanization and vulcanizing agents. L.: Chemistry, 1968. 291 p. (in Russian)]

[15] Шварц А.Г. Динзбург Б.Н. Совмещение каучуков с пластиками и синтетическими смолами. М.: Химия, 1972. 224 c. [Shvarts A.G. Dinzburg B.N. Combination of rubbers with plastics and synthetic resins. M.: Chemistry, 1972. 224 p. (in Russian)]

[16] Zaborski M., Slusarski L. The effect of network structure of elastomers on their interactions with plastomers. Polimery, 1996, 41(1), 43-48.

[17] Тарасевич Б.Н. ИК-спектры основных классов органических соединений [Электронный ресурс] - Режим доступа: http://www.chem.msu.su/rus/teaching/tarasevich/Tarasevich_ 
IR_tables_29-02-2012.pdf [Tarasevich B.N. IR spectra of the main classes of organic compounds [Electronic resource] - Access: http://www.chem.msu.su/rus/teaching/tarasevich/ Tarasevich_IR_ tables_29-02-2012.pdf (in Russian)]

[18] Наканиси К. Инфракрасные спектры и строение органических соединений. М.: Мир, 1965. 216 c. [Nakanishi K. Infrared spectra and the structure of organic compounds. M.: Mir, 1965. 216 p. (in Russian)]

[19] Бочаров В.Н., Бурейко С.Ф., Колль А., Роспенк М. Квантовохимические расчеты структуры молекулы дифенилгуанидина и экспериментальные исследования его таутомерного строения в растворе. Журнал структурнойхимии, 1998, 39(4-6), 618-625 [Bocharov V.N., Bureyko S.F., Koll' A., Rospenk M. Quantum-chemical calculations of the structure of a diphenylguanidine molecule and experimental studies of its tautomeric structure in solution. Journal of Structural Chemistry, 1998, 39(4-6), 618-625 (in Russian)] 